\title{
On teaching styles of water educators and the impact of didactic training
}

\author{
A. Pathirana ${ }^{1}$, J. H. Koster ${ }^{1}$, E. de Jong ${ }^{1}$, and S. Uhlenbrook ${ }^{1,2}$ \\ ${ }^{1}$ UNESCO-IHE Institute for Water Education, Delft, The Netherlands \\ ${ }^{2}$ Delft University of Technology, Section of Water Resources, Delft, The Netherlands
}

Correspondence to: A. Pathirana (a.pathirana@unesco-ihe.org)

Received: 20 January 2012 - Published in Hydrol. Earth Syst. Sci. Discuss.: 8 March 2012

Revised: 29 August 2012 - Accepted: 19 September 2012 - Published: 17 October 2012

\begin{abstract}
Solving today's complex hydrological problems requires originality, creative thinking and trans-disciplinary approaches. Hydrological education that was traditionally teacher centred, where the students look up to the teacher for expertise and information, should change to better prepare hydrologists to develop new knowledge and apply it in new contexts. An important first step towards this goal is to change the concept of education in the educators' minds. The results of an investigation to find out whether didactic training influences the beliefs of hydrology educators about their teaching styles is presented. Faculty of UNESCO-IHE has been offered a didactic certification program named university teaching qualification (UTQ). The hypothesis that UTQ training will significantly alter the teaching style of faculty at UNESCO-IHE from expert/formal authority traits towards facilitator/delegator traits was tested. A first survey was conducted among the entire teaching staff (total 101, response rate $58 \%$ ). The results indicated that there are significantly higher traits of facilitator and delegator teaching styles among UTQ graduates compared to faculty who were not significantly trained in didactics. The second survey which was conducted among UTQ graduates (total 20, response rate $70 \%$ ), enquiring after their teaching styles before and after UTQ, corroborated these findings.
\end{abstract}

\section{Introduction}

In higher education two types of knowledge generation approaches can be identified: discipline-oriented studies and problem-oriented (mission-oriented) studies (Ashby, 1973; Short, 2002). Traditional higher education institutes excelled in preparing graduates with the former approach. Ashby (1972) noted "The incongruence between the discipline-oriented training which most students receive and the mission-oriented activities in which many of them wish to engage after graduation, is one of the causes of our present discontents with higher education. So there is a need (if we can do it) to include in higher education some experience which will help people to learn the art of [mission-oriented] sort of decision making which includes scientific data, estimates of practicality, and a framework of ethical principles". Looking back today, this is a statement describing the predicament we are facing in hydrological education. Hydrology related challenges are by nature broad, local-specific, unique and multidisciplinary (e.g. Uhlenbrook, 2006; Wagener et al., 2010). Solving them calls for skills that go beyond the knowledge that could be expected to be obtained by studying a single discipline as well as well developed integrative skills and a mix of competencies (Uhlenbrook and de Jong, 2012). Note, that we apply a very wide definition of hydrology in this paper, which is following the terminology used in the UNESCO International Hydrology Programme (IHP) and includes fields such as hydraulics, water management/governance, aquatic ecology, sanitary engineering, water supply engineering and hydrological modelling in a wider sense.

Largely due to tradition, world-wide higher education programs related to hydrology still remain very much disciplineoriented entities: they focus mostly on the fundamental knowledge of processes, theories and models, but often pay little attention to training students in the art of applying these to real-world problems. But we do expect the graduates to perform in the real world solving mission-oriented problems. 
The discipline we term as hydrology is fast shifting its boundaries, challenging its practitioners and researchers to change their approaches swiftly (Kleinhans et al., 2010). It has been long accepted that the "science on which solutions to present and future global water problems must be based does not fall within the purview of a single discipline but rather is truly multidisciplinary and inherently interdisciplinary" (Jury and Vaux, 2005).

Solving a complex hydrological problem typically involves several steps: (1) define, identify and analyse the problem, (2) identify or develop possible solutions and select the optimal one and, (3) implement the solution. In the traditional classroom, we routinely forgo step 1 and often glossover step 2 and spend considerable time on step 3. As an example, students may spend time learning various simplifications of shallow water equation and how it is numerically modelled in one, two and three dimensions. While being essential fundamental knowledge for a flood modeller, this itself does not fully prepare a student to be a problem-solver in a real-world environment. Making a good flood modeller should start with exposing the students to the problem of flooding, through means like case studies, examples and selfguided exploration. This exposure stimulates the interest of the student to learn how to model floods as an important step in flood modelling and flood management. This is an essential step that should not be hurried or treated superficially. The learning of fundamentals then comes as a logical step in a sequence of steps in solving a tangible problem. After the fundamentals the students should be guided to revisit the initially introduced problems and critically evaluate how the modelling techniques they learned help solving the problems and to identify the remaining knowledge gaps. At this stage they should learn how their contribution could potentially help solving a much broader flood management problem that is multidisciplinary. Among others, skills such as understanding the roles of different experts and effectively communicating results with them and other stakeholders has to be covered. An in-depth discussion of the competency profile of hydrologists and other water professionals (i.e. Tshape model) is provided by Uhlenbrook and de Jong (2012).

It is important to critically look at approaches to water education and take action where necessary to ensure that the hydrology education experience has an adequate degree of "problem-oriented" skill development. One of the important actions in this regard is to give the students the freedom to explore and develop knowledge and in the process to develop the necessary mission-oriented skills. Looking up to the teacher for expertise is not a model that fits very well with this paradigm. As the teachers' approach to teaching influences the students' development trajectories, it is useful to look at how we teach hydrology in order to understand what needs to be improved in hydrology education. While content is indisputably important in education, teaching styles employed are also (if not more) crucial in problem-oriented skill development.

\subsection{Teaching styles}

Each university teacher approaches teaching in a unique style. Similar to any other profession like engineering or architecture, teachers demonstrate different styles of interacting in their profession and possess different beliefs about their approach. There have been numerous attempts to introduce taxonomy to teaching-styles. Solomon (1966) attempted a classification of university teachers using terms like "warm", "flamboyant", "dry", etc. Bennett (1976) reported a study including 1258 respondents from primary school education using a classification approach based on 28 questions. Traditionally teaching-style studies have attracted their share of criticism of being "confused with affectation, denigrated as a kind of posturing to mask a lack of substance, or tolerated as a natural manifestation of personal eccentricities" (Eble, 1980).

Towards the 1990's more formal classifications can be seen in the didactic literature. Quirk (1994) used a four term classification (assertive, suggestive, collaborative and facilitative) in his teaching-style taxonomy of clinical education in medicine. Later Grasha $(1994,1996,2009)$ developed a more elabo-rate method based on five styles (expert, formal authority, personal model, facilitator and delegator) that define four clusters of teaching-styles: (Expert/Formal Authority, Personal Model/Expert/Formal Authority, Facilitator/Personal Model/Expert, Delegator/Facilitator/Expert).

The expert teacher is mainly concerned that the students receive correct information and are well prepared in their discipline. In hydrology this is a teacher who focuses on teaching processes (e.g. evaporation, infiltration etc.), theories (e.g. Richards equation), models (e.g. Green-Ampts model for infiltration), etc. Naturally, the style allows for the efficient transfer of knowledge. A main disadvantage is that it focuses more on the outcome than on developing the thought process leading to that outcome. The formal authority teacher focuses on following relevant standards (e.g. using design codes for infiltration facility planning). A disadvantage of this style is that it can lead to rigid, standardized and inflexible teaching (Grasha, 1996). A personal model teacher focuses on setting an example rather than prescribing (e.g. demonstrates how a professional solves infiltration problems by means of examples). The feeling of inadequateness if unable to live up to the standards of the instructor is a downside of this approach. Lastly, the facilitator and delegator styles portray the teacher as a guide, encouraging students to explore knowledge (e.g. let students explore by reading, websearch, discussions, etc.). Less experienced students as well as those unused to this approach may feel confused and directionless with this autonomy.

Felder and Silverman (1988) in their popular paper attempted to link psychological traits of students and their learning styles with teaching-styles. They concluded that "Learning styles of most engineering students and teaching styles of most engineering professors are in-compatible in 
several dimensions. Many or most engineering students are visual, sensing, inductive, and active, and some of the most creative students are global; most engineering education is auditory, abstract (intuitive), deductive, passive, and sequential. These mismatches often lead to poor student performance, professorial frustration and a loss to society of many potentially excellent engineers". This study and others since (e.g. Grasha and Yangarber-Hicks, 2000) have emphasized the importance of understanding the teaching and learning styles to gain more insights into their interplay in the process of university education.

\subsection{Appropriate mix of teaching styles for hydrology?}

Effective education in the fields of hydrology needs a combination of teaching styles of expert, formal authority, personal model, facilitator and delegator. Take the example of design of urban storm drainage systems: the students should be able to understand the physical processes, theories governing the flow of water in conduits and methods of calculation (e.g. computer models). They may also need to understand the engineering practice, norms regulation and standards. Last but not least, there are skills beyond the technical aspects that may best be conveyed by demonstrating to the students how some things are done successfully through studying real-world cases. Expert, formal-authority and personalmodel aspects of teaching-styles could be useful for achieving these. However, even for achieving these "basic" knowledge and skills, in addition to traditional teaching, facilitating students to explore, construct and internalize knowledge could be effective (Felder and Silverman, 1988). Facilitator and delegator traits could be useful in this context. Facilitating and delegation can also work for stimulating students for learning by developing their interest to the subject. However, the real need for these traits comes into play when the educator is faced with the problem of helping students develop the advanced skills to effectively apply what they have learned. In the case of design of urban storm drainage systems, these may include: critically analyse a design, communicate the essential aspects of a design to a multidisciplinary team of experts, develop a "feeling" for accuracy of modelling results. These skills are also important when the students move to the next stage of their academic programme, namely, conducting scientific research towards writing a masters thesis (Pathirana et al., 2012). Encouraging the students to take initiative in a supporting environment can help substantially in developing such skills. In this context we argue that, while one teaching-style is not inherently superior to others, it is important for hydrology educators to also learn to be facilitators and delegators. This is particularly important owing to the fact that hydrology educators were historically not very good at either.

\subsection{University teaching qualification (UTQ) at UNESCO-IHE}

Each year UNESCO-IHE enrols some two hundred MSc students largely from developing countries in Asia, Africa and Latin America in its master programmes in the field of water and environment. The programmes and specialisations are mainly engineering oriented, although some focus more on sciences or have significant social sciences components. The vast majority of these students are mid-career professionals who, upon graduation, return to their countries and often play important roles in shaping the policy and practice in the water sector in these countries. The fact that the graduates of UNESCO-IHE end up in working in diverse geographical, economic and cultural settings makes it even more important to focus their education on the development of skills and competencies (cf. Uhlenbrook and de Jong, 2012) as opposed to merely delivering knowledge. The breadth and nature of the water problems they may have to solve in their professions are so large and diverse that it is practically impossible to equip them, during their education, with all the knowledge and techniques needed to solve them. It is important for UNESCO-IHE graduates to develop the ability to face, understand and solve water problems that are novel and challenging. It is therefore our belief that in order to foster student development in this direction, a shift of focus amongst teaching staff from expert/formal authority traits towards facilitator/delegator traits is necessary. While this may be seen as a universal requirement in higher education, it is particularly important for the learning environment at UNESCOIHE due to its thematic-focus (water) and global mission, and its heterogeneous student population that is characterized by a large cultural, ethnic, religious and language diversity.

In order to achieve this shift, and starting from 2010, faculty of UNESCO-IHE is currently offered a didactic certification program named university teaching qualification (UTQ), a programme aimed to develop didactic skills of the teaching staff in the direction of facilitating active learning in higher education. The UTQ programme focuses on "constructive alignment", where the student constructs her/his own learning through relevant learning activities. It stimulates the lecturer to create a learning environment that supports the learning activities appropriate to achieving the desired learning outcomes. In other words, the UTQ training intends to stimulate UNESCO-IHE faculty to develop facilitator/delegator teaching styles. A programme aimed to develop didactic skills of the teaching staff in the direction of facilitating active learning in higher education. UTQ candidates after an introductory meeting with the UTQ coach - who is a qualified educationalist - participate in a refresher course on didactics (total about $10-12 \mathrm{~h}$ of contact time). Then with the help of the coach they plan the UTQ portfolio activities. They spend around $130 \mathrm{~h}$, typically spread over a one year period, compiling the portfolio, which is then assessed by a 
portfolio committee. The UTQ programme is described in detail in Appendix B.

The UTQ program is based on the theory of constructive alignment - a type of outcome based education, used for devising teaching and learning activities, and assessment tasks, that directly address the learning outcomes intended in a way not typically achieved in traditional lectures, tutorial classes and examinations (Biggs and Tang, 2011). Constructive alignment is a combination of two principles: first, constructivism, which states that learning, is an active, constructive process where the learner actively constructs knowledge. Then there is the concept of "Aligned Teaching" stating that for effective learning the stated learning objectives, activities for achieving those objectives and the assessment of the level of achievement should be consistent - or aligned - with each other. It stimulates the lecturer to create a learning environment that supports the learning activities appropriate to achieving the desired learning outcomes rather than focusing on transferring on knowledge. In other words, the UTQ training intends to stimulate UNESCO-IHE faculty to develop facilitator/delegator teaching styles.

After running the UTQ program for two years and producing about 20 graduates, we were interested to know the impact of the program. An important logical step in this direction is to understand the profile of the faculty in relation to UTQ and didactic training in general. Our working hypothesis in this study was that UTQ training will significantly alter the teaching-styles of faculty at UNESCO-IHE in a direction that fosters learning styles that lead to the development of necessary skills to solve the broad, multidisciplinary and interdisciplinary problems in the water sector. We based our study on Grasha's (1996) teaching style classification. The hypothesis translates then into a question whether the UTQ program was instrumental in shifting the teaching styles from the expert/formal authority towards facilitator/delegator traits.

In the next section, we discuss the approach we used to test our hypothesis. Then we present the statistical analysis of the data and the results. Finally, we discuss the results and arrive at conclusions. We also discuss the limitations of our approach, the possible peculiarities of the population ("UNESCO-IHE faculty") and the validity of the conclusions beyond the population studied.

\section{Methodology}

The most straightforward method for testing our hypothesis is to examine the population before and after UTQ (treatment). However, in the present case there are several problems in using this approach. Unless the participants were tested before UTQ (which had not been done) there is no way of objectively ascertaining the changes between before and after. It is of course possible to question the UTQ graduates about their personal "before" and "after" situation.
However, this type of survey instrument is prone to be influenced by issues related to personal judgment of individuals. The other alternative is to examine the differences between faculty who have undergone UTQ and those who did not. This approach has the weakness that any non-randomness of selection/volunteering of staff for UTQ might have an impact on the results. After careful consideration of both approaches, we decided to apply a combination of the two.

First, we conducted a detailed survey on all faculty of UNESCO-IHE and examined whether there are statistically significant differences among the two classes (UTQ vs. others). Then we used a follow up survey among UTQ graduates to see if the outcome validates the results of the first survey.

We based our analysis of teaching-style on the five styles defined by Grasha (1996). In the first survey, we used the validated survey instrument comprising of 40 questions (Teaching Styles Inventory: Version 3.0, Grasha, 1996). We also questioned the participants on their academic background (teaching experience in years, current level of engagement in teaching as number of hours per year, field of expertise (undergraduate major) of the respondent, previous experience in didactic training including UTQ, other programs like UTQ, seminars and workshops). Further we also asked them to rate (on a five point scale) their inclination to have future didactic training and belief whether they will benefit from such training. Optionally the respondents could state their gender and geographical area where they did (a) most of their schooling, (b) their undergraduate degree, and (c) their highest post-graduate degree.

In the second survey, after describing the nature of each style (after Grasha, 1996, p. 154, Table 4-1), we invited the UTQ graduates to assess their "level of belonging" to each class before and after UTQ training. Further we asked them to provide descriptive answers to the following questions:

- What were the most important things you learned?

- What (if any) did you change in your classroom behavior and interaction with students, compared to what you did before you followed the UTQ course?

- If yes, has your new way of teaching lead to improvements - for yourself and for the students? (Yes/No). In what way?

- If nothing substantially changed, why not?

Further, we also asked the respondents to rate on a five point scale whether they disagreed/agreed to the following propositions.

- The UTQ program was useful to you;

- you learned new things during the course;

- the UTQ trainer stimulated your learning;

- your colleagues stimulated your learning; and 
- you have applied what you learned in the course in your own teaching activities.

Both surveys were conducted online (Lime Survey, 2011) anonymously, but using a token-based control system so that only invitees could respond. There was no opportunity for multiple responses from the same invitee.

\section{Results}

\subsection{Survey 1}

UNESCO-IHE has around 100 academic staff of which some 90 are significantly involved in teaching. Out of the total of 68 people that responded, ten responses were incomplete and therefore 58 records were available for analysis. The optional questions on gender and educational background were skipped by seven and eight respondents, respectively - making the sample size somewhat smaller for those variables. The results were analysed using a statistical analysis tool (GRETL; Cottrell and Lucchetti, 2011). The answers to the forty questions in the Grasha's teaching-style part were used to compute the degree of belonging to each of the five styles: expert, formal authority, personal model, facilitator, and delegator. Category choices for teaching experience and current level of teaching engagement were converted to interval variables (Table A1). The multi-choice for previous didactic experience was added up giving weights of 1,2 , and 4 for seminars/workshops once, more than once and longer UTQ type certification trainings, respectively. For example if a responded has attended multiple seminars, a workshop and UTQ, she would be assigned $1+2+4=7$. All rating scales (e.g. would you like to undergo in didactic training in the future?) were five choice (ranging from "strongly-disagree" to "strongly-agree") and were converted to interval values ranging from 1 to 5 .

The educational background questions were used to derive four categorical variables: Only-EUR: whether or not a respondent was exclusively educated in Europe, Only-West: exclusively in the "west" (here "west" defined as Europe, North America and Oceania), Only-NW: exclusively "NonWest" and, West + NW: mixed.

Figure 1 shows the distributions of important variables in the sample. Approximately $50 \%$ of the sample had more than $10 \mathrm{yr}$ of teaching experience (Fig. 1a). Forty were teaching more than 25 contact hours per year out of which, 18 did more than 70 contact hours (Fig. 1b). The field of education of the sample was largely engineering, followed by science (Fig. 1c). Among those who indicated the gender, there were twice as many men than women (Fig. 1d). The sample consisted of predominantly European educated (school, undergraduate and post-graduate) teachers (37 out of 58). Only two respondents had had exclusively non-western education (Fig. 1e). Slightly more than $50 \%$ of the sample had undergone significant didactic training sometime during their
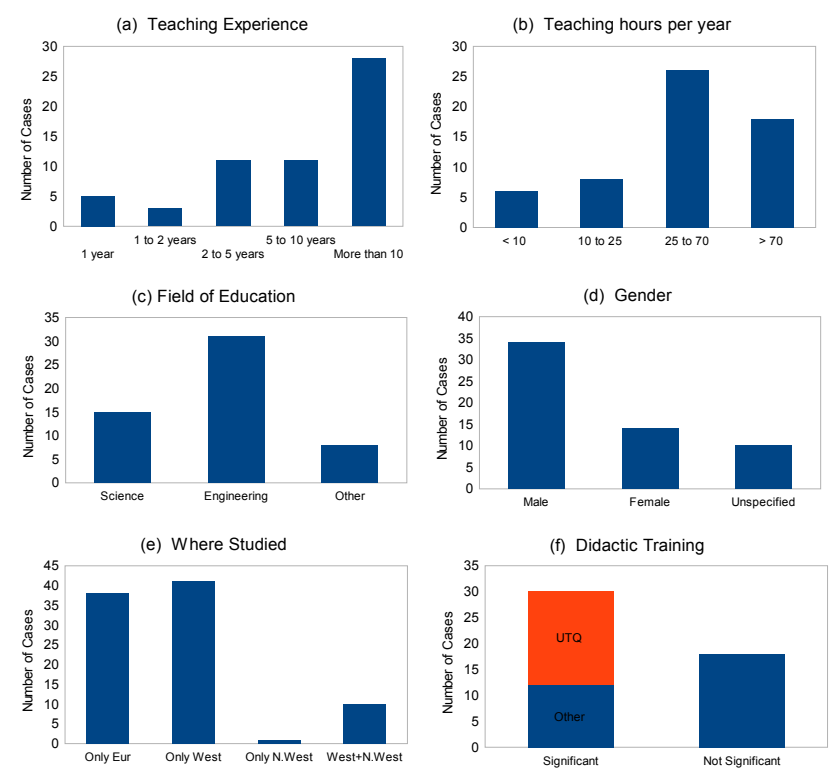

Fig. 1. Basic statistics of the survey sample. (a) Number of years of teaching experience. (b) Current hours taught per year. (c) Field of undergraduate degree of the respondent. (d) Gender. (e) Region where educated (school, undergraduate and postgraduate). (f) Didactic training. Significant: who have undergone significant didactic training (includes UTQ graduates and those who responded as possessing significant didactic training from other sources). Nonsignificant: those who do not have undergone significant didactic training.

career; out of which 17 had completed the UTQ program (Fig. 1f).

We examined the correlations between all interval variables (all except gender and educational background which, were categorical). For the sample size of $58, p=5 \%$ critical value for correlation is 0.26 . We observed strong correlations among some of the five teaching styles. Given the fact that many teachers demonstrate a combination of several of these styles - referred to as "clusters" (Grasha, 1996; Lucas, 2005; Lucas and Wright, 2009), this is to be expected (details about cor-relation analysis are given in Appendix A).

Next we examined whether there are statistically significant differences in teaching-styles between UTQ graduates and faculty who were not significantly subjected to didactic training. In this analysis, we ignored the respondents who had significant didactic training other than UTQ, due to the fact that we did not have adequate information on the nature of such training to classify them to the same group as UTQ graduates.

Due to the difficulty of making the normality assumption for all the variables in the survey outcome, we selected Mann-Whitney U (MWU) test (also known as the Mann-Whitney-Wilcoxon or Wilcoxon rank-sum test) to test the differences of various categories of respondents. MWU is a non-parametric statistical hypothesis test for assessing 
whether one of two samples of independent observations tends to have larger values than the other and can be applied for unequal samples (Mann and Whitney, 1947). GRETL's MWU test reports the p-value of the test and U statistic (among other parameters). The results of the MWU tests are given in Table A2.

Figure 2 shows the differences between UTQ trained faculty vs. those who did not have significant didactic training. It confirms that UTQ trained faculty belongs significantly more to the facilitator $(p<10 \%)$ and delegator $(p<1 \%)$ types. No significant differences were found for the other categories.

Interestingly, partitioning based on gender also showed significant differences in teaching styles. Figure 3 shows the differences between male $(\mathrm{M})$ and female $(\mathrm{F})$ respondents for the five teaching-styles and their inclination to undergo didactic training. Female respondents had a lesser degree of "formal authority" $(p<1 \%)$ and "personal model" $(p<5 \%)$ traits compared to male respondents. Female respondents also liked to have didactic training significantly $(p<5 \%)$ more than the male respondents.

We also found that the years of experience in teaching did not have a significant $(p<20 \%)$ impact on teachingstyles, although more experience significantly reduced ( $p<$ $5 \%)$ the inclination to have didactic training. Further, the educational background of the faculty (exclusively western vs. mixed + non-Western) did not have any significant $(p<$ $10 \%)$ impact on teaching-styles or the inclination to have didactic training.

\subsection{Survey 2}

The key finding of the first survey towards our hypothesis was that the degree of belonging to the facilitator and delegator style is significantly higher amongst UTQ trained faculty compared to those who did not (yet) undergo significant didactic training. We conducted the second survey to corroborate this finding.

First, we used respondents' own assessment of their degree of belonging to each of the five teaching-styles before and after UTQ. While the styles expert, formal authority and personal model did not show statistically significant differences, those of facilitator and delegator did show significant ( $p=0.016$ and $p=0.007$, respectively) increases (the Mann-Whitney U-tests results are given in Table A5). Figure 4 shows the five teaching-styles pre and post UTQ.

We also did a compilation of answers to the descriptive questions of the survey (provided as a Supplement to this manuscript), which also showed similar opinions about what has changed. In general all staff members who participated in the UTQ programme evaluated it as a positive experience. Teachers have become more aware of the fact that teaching should be primarily about what students learn and much less about what they teach. As one teacher indicated (see

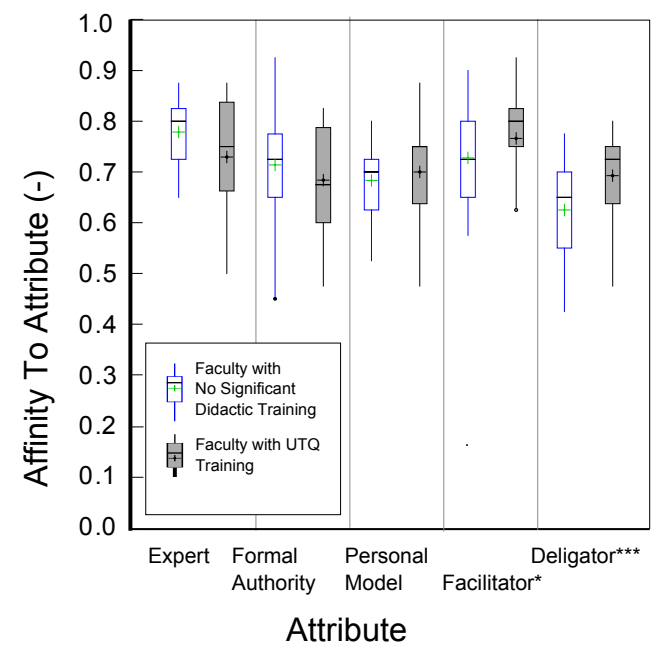

Fig. 2. Differences of teaching-style between UTQ trained respondents and those who did not have significant didactic training. * indicates $p<10 \%,{ }^{* *} p<5 \%$ and ${ }^{* * *} p<1 \%$. Horizontal bar indicates mean and the cross, the median. Boxes show 25th and 7 th percentile.

Supplement): "I can teach as much as I like but if this does not lead to learning, then it is all in vain".

\section{Discussion}

\subsection{Major findings}

The first survey clearly showed that the degree of belonging to the facilitator and delegator teaching styles is significantly higher among UTQ graduates compared to faculty who were not significantly trained in didactics. The second survey, which was conducted using a completely different approach (and was therefore independent of the first survey) showed that according to the judgment of the UTQ graduates, their degree of belonging to the facilitator/delegator styles increased significantly after UTQ training. Therefore, we can accept the hypothesis that UTQ training significantly influences teaching styles of UNESCO-IHE faculty, enhancing their facilitator and delegator styles.

Is is interesting to compare this findings with the similar study of Postareff et al. (2007). They did a statistical study of impact of university teachers' pedagogical training on approaches to teaching and self-efficacy beliefs using some 200 faculty members of University of Helsinki. The found that even when the effect of teaching experience is held constant, there was a positive impact of a siginficant level of didactic training (of more than 30 European Credit Transfer System credits) in shifting the focus of teaching from information transmission/teacher-focused approach to teaching, towards a more "conceptual change/studentfocused" approach. While the terminology used in that study 


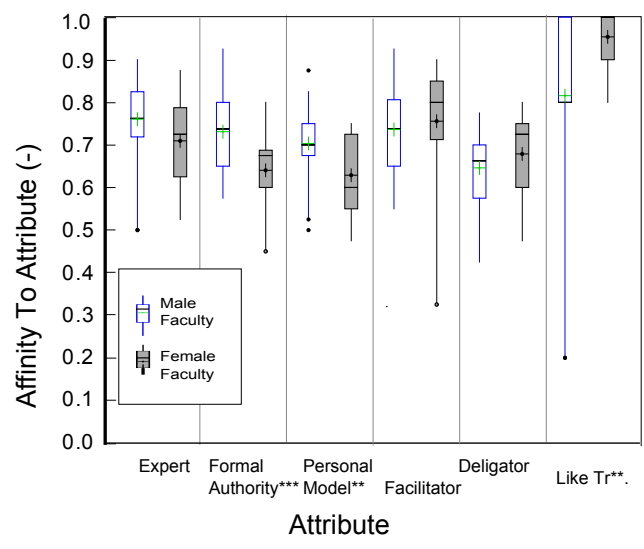

Fig. 3. Differences in teaching-style and inclination to have didactic training between male and female respondents. $*$ indicates $p<10 \%,{ }^{* *} p<5 \%$ and ${ }^{* * *} p<1 \%$.

are different from the current one, the findings are similar in a generic sense.

The first survey also revealed some other interesting traits. First, women showed a significantly lesser degree of belonging to the formal authority and personal model teaching styles than men. They also showed a significantly higher degree of interest to follow didactic training. Lastly, the educational background of teaching staff (West vs. Nonwest/Mixed) did not influence the teaching styles.

\subsection{Learning - the flip side}

The teaching style is one of the many important parameters that determine success of an educational program; in other words, the degree to which the students achieve the learning objectives. Ultimately, what matters is the quality and effectiveness of learning, which has a lot to do with the attitudes of the students. These attitudes in-turn are largely governed by their background, experiences, habits and expectations. In an organization like UNESCO-IHE, the heterogeneity of the student background in terms of geographic origin, education system, professional experience, etc. is only reasonable to assume that there are considerable differences among individual students' attitudes towards learning (Uhlenbrook and de Jong, 2012). A majority of UNESCO-IHE students are mid-career professionals who have been working in the sector (industry, government, academia, etc.) for a minimum period of years (often much longer) after their bachelor's degree (Pathirana et al., 2012). They are of considerably higher average age than the post-graduate students of a classical university and, therefore, largely experienced only in the traditional teacher-led mode of education. The need for changing teaching styles is driven by the needs of the profession of hydrology (Sect. 2.1): attempting to address the nature of problems that future professional have to solve and the skills they need to effectively do that. We are of firm opinion that the

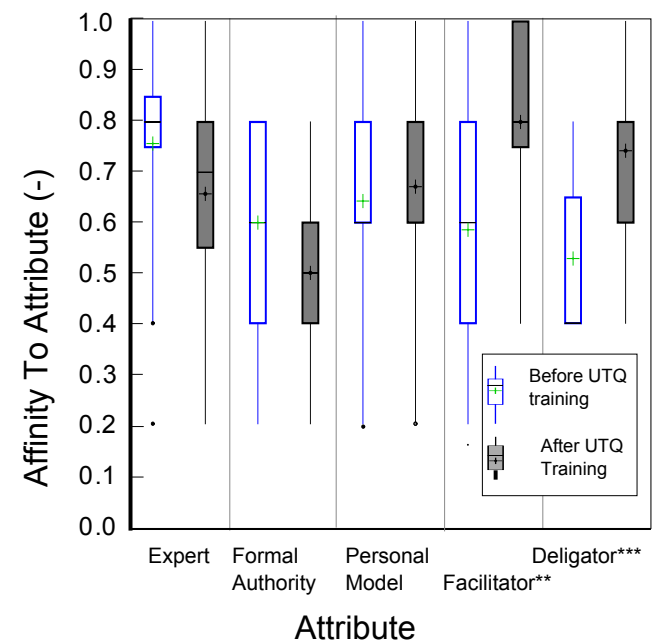

Fig. 4. UTQ graduates beliefs on what has changed in their teaching-styles after UTQ compared to before. ${ }^{* * *} p<1 \%$, ${ }^{* *}$ $p<5 \%$. Y-axis is on a scale from 0 to 1.0 .

employment of more facilitator and delegator traits by teachers will improve ability of the graduates to face up to these challenges. However, it is extremely important for the educator to be aware of the fact that by doing so, they may be forcing some students to get out of their "comfort zone". Gradual introduction of change with careful monitoring of achieving the learning outcomes and effective mentoring programs are therefore recommended. It is also not expected that an improvement of immediate student feedback (e.g. student evaluations) as a result of such a shift may be observed - in the short-term, even the opposite might happen!

\subsection{Limitations}

The study has some limitations. In the first survey we implicitly assumed that the sample of faculty that had followed and completed the UTQ program was largely random, and that therefore existing traits of the faculty did not influence the differences that we observed. We discussed this issue with the department heads who were responsible for the selection of staff for following UTQ. In almost all cases the teaching performance of the faculty or their teaching styles had not been considered in the selection process. The final decision to follow the course was, however, a joint one. This could have implied that those that followed UTQ were inherently more open to didactic training. However, the inclination to follow didactic training was not significantly different $(p=30 \%)$ between the groups UTQ trained and other faculty. Note that we do not have adequately large samples to conduct a nonparametric similarity (e.g. Kolmogorov-Smirnov) test.

We need to question whether the statistically significant differences of teaching styles do imply a significant practical importance. For example the mean value of delegator style increases from 0.52 to 0.75 due to UTQ training (Fig. 4), a 
Table A1. The scales used to convert some choices to interval variables for statistical analysis.

\begin{tabular}{ll}
\hline Option in the survey & $\begin{array}{l}\text { Interval } \\
\text { variable } \\
\text { value }\end{array}$ \\
\hline $\begin{array}{l}\text { How many years have you been engaged in teaching at } \\
\text { university/post-graduate/equivalent level by now? }\end{array}$ \\
\hline Less than a year & 1 \\
Between a year and two & 2 \\
Between two years and five years & 4 \\
Between five to ten years & 6 \\
More than ten years & 8 \\
\hline Are you currently engaged in teaching? & \\
Choose one of the following answers & 1 \\
\hline No & 2 \\
Yes, less than $10 \mathrm{~h}$ a year. & 4 \\
Yes, between 10 and $25 \mathrm{~h}$ a year. & 6 \\
Yes, between 25 and $70 \mathrm{~h}$ a year. & $(+1 /+2)$ \\
Yes, More than $70 \mathrm{~h}$ & +4 \\
\hline Have you undergone training on teaching? & \\
\hline A seminars/workshop (one/2 or more) & \\
Certification courses (UTQ or similar) & \\
\hline
\end{tabular}

Table A2. Correlations among teaching styles for the total sample of Survey 1 (58 samples, significant $(5 \% *)$ correlations $>0.26)$.

\begin{tabular}{lcccc}
\hline & $\begin{array}{c}\text { Formal } \\
\text { authority }\end{array}$ & $\begin{array}{c}\text { Personal } \\
\text { model }\end{array}$ & Facilitator & Delegator \\
\hline Expert & $\mathbf{0 . 4 8}$ & $\mathbf{0 . 6 2}$ & 0.13 & 0.04 \\
Formal authority & & $\mathbf{0 . 5 4}$ & $\mathbf{0 . 3 0}$ & 0.04 \\
Personal model & & & $\mathbf{0 . 3 4}$ & $\mathbf{0 . 3 7}$ \\
Facilitator & & & & $\mathbf{0 . 7 3}$ \\
\hline
\end{tabular}

$45 \%$ increase. However, it is difficult to explain what exactly this $45 \%$ increase implies in practice, and what the implications are of the learning outcomes for the students.

Our study was limited to a single educational institute. Although UNESCO-IHE faculty consists of a diverse group of individuals from various backgrounds (Fig. 1), it may not be representative for the wider hydrology teaching profession.

\section{Conclusions}

The results of this study have confirmed that the UTQ didactic training of UNESCO-IHE staff is producing the desired results in as far as it concerns a shift towards the sense of belonging to the desired teaching style, namely one that emphasizes facilitator and delegator traits. To what extent this shift in the sense of belonging translates into a shift in the teaching style actually applied in practice, remains to be seen. It is therefore the intention of the authors to conduct a follow-up
Table A3. Correlations among teaching styles (Survey 1) for UTQ graduates (27 samples, significant $\left(10 \%{ }^{*}\right)$ correlations $\left.>0.389\right)$.

\begin{tabular}{lcccc}
\hline Formal authority & $\begin{array}{c}\text { Personal } \\
\text { model }\end{array}$ & Facilitator & Delegator & \\
\hline Expert & $\mathbf{0 . 5 6}$ & $\mathbf{0 . 7 3}$ & 0.22 & 0.17 \\
Formal authority & & $\mathbf{0 . 6 5}$ & $\mathbf{0 . 4 1}$ & 0.17 \\
Personal model & & & $\mathbf{0 . 3 9}$ & 0.27 \\
Facilitator & & & & $\mathbf{0 . 8 2}$ \\
\hline
\end{tabular}

Table A4. Correlations among teaching styles (Survey 1) for faculty without significant didactic training (27 samples, significant $(5 \%)$ correlations $>0.367)$.

\begin{tabular}{lcccc}
\hline Formal authority & & $\begin{array}{c}\text { Personal } \\
\text { model }\end{array}$ & Facilitator & Delegator \\
\hline Expert & $\mathbf{0 . 4 4}$ & $\mathbf{0 . 6 0}$ & $\mathbf{0 . 5 2}$ & $\mathbf{0 . 5 1}$ \\
Formal authority & & $\mathbf{0 . 3 7}$ & 0.32 & 0.06 \\
Personal model & & & 0.27 & $\mathbf{0 . 5 7}$ \\
Facilitator & & & $\mathbf{0 . 6 6}$ \\
\hline
\end{tabular}

study into the actual teaching styles of UNESCO-IHE staff pre- and post-UTQ.

\section{Appendix A}

\section{Correlation analysis}

We examined the correlations between the five teaching style scores. Grasha (1996) identifies four clusters of teaching-styles - (a) expert/formal authority, (b) personal model/expert/formal authority, (c) facilitator/personal model/expert, (d) delegator/facilitator/expert - of university faculty. If this type of clustering applies to UNESCO-IHE faculty, then we should expect significant correlations among the five categories. There are significant correlations of personal model with all remaining four categories, apart from that correlation of expert with (formal authority), formal authority with (expert, facilitator) and facilitator with (formal authority and delegator). The significant correlation pairs are different in the case of faculty with UTQ training and without significant didactic training (Table A1). However, we later demonstrate these differences using other statistical tests.

Other interesting significant correlations are the negative correlation $(-0.39)$ between experience and inclination to follow UTQ type of training. Similar correlation $(-0.33)$ exists between perceived benefit from UTQ and experience. Experienced teachers tend to teach more time at UNESCOIHE (0.45) and values additional didactical training less. There is a positive correlation ( 0.33$)$ between didactic training and delegator style. 
Table A5. Results of the Mann-Whitney U-test.

\begin{tabular}{|c|c|c|}
\hline \multicolumn{3}{|c|}{ SURVEY 1} \\
\hline Gender & p-value & U statistic \\
\hline Expert & 0.128 & 176.5 \\
\hline Formal authority & 0.007 & 122.0 \\
\hline Personal model & 0.025 & 143.0 \\
\hline Facilitator & 0.206 & 188.5 \\
\hline Delegator & 0.206 & 188.5 \\
\hline Like to have didactic training & 0.013 & 132.5 \\
\hline \multicolumn{3}{|c|}{ UTQ vs. non-didactic-trained } \\
\hline Expert & 0.323 & 188.5 \\
\hline Formal authority & 0.323 & 188.5 \\
\hline Personal model & 0.268 & 183.5 \\
\hline Facilitator & 0.081 & 157.0 \\
\hline Delegator & 0.009 & 120.5 \\
\hline Like to have Didactic training & 0.294 & 186.0 \\
\hline \multicolumn{3}{|c|}{ High experience vs. low } \\
\hline $\begin{array}{l}\text { Like to have Didactic training } \\
\text { All other variables had } p>20 \%\end{array}$ & 0.036 & 82.0 \\
\hline $\begin{array}{l}\text { Exclusively western trained vs. } \\
\text { others (mixed + non-western) } \\
\text { All variables had } p>10 \% \\
\text { SURVEY } 2 \\
\text { Before vs. after UTQ }\end{array}$ & $\begin{array}{l}\text { Did not have any } \\
\text { significant differences }\end{array}$ & \\
\hline Facilitator & 0.016 & 37.5 \\
\hline Delegator & 0.007 & 32.0 \\
\hline All other variables had $p>10 \%$ & & \\
\hline
\end{tabular}

Active learning and aligned teaching: university teaching qualification programme for lecturers at UNESCO-IHE.

\section{Appendix B}

\section{Active learning and aligned teaching}

\section{B1 University Teaching Qualification programme for lecturers at UNESCO-IHE}

This document describes a programme designed to provide senior lecturers at UNESCO-IHE with the opportunity to obtain their UTQ (University Teaching Qualification) certificate.

\section{Introduction}

Teaching and learning take place in an environment of classrooms, buildings, and labs. In a good educational system, all aspects of teaching, learning and assessment are tuned to support high level learning, so that students are encouraged to use higher-order learning processes. "Constructive alignment" (CA) is such a system. It is an approach to curriculum design that optimises the conditions for quality learning.

"Constructive alignment" starts with the notion that the learner constructs his or her own learning through relevant learning activities. The teacher's job is to create a learning environment that supports the learning activities appropriate to achieving the desired learning outcomes. The key is that all components in the teaching system - the curriculum and its intended outcomes, the teaching methods used, the assessment tasks - are aligned to each other. All are tuned to learning activities addressed in the desired learning outcomes (Biggs and Tang, 2011).

University Teaching Qualification programme (UTQ) is offered to UNESCO-IHE faculty as an aid to improving their teaching in general and specifically to apply CA in their teaching activities. Each participating faculty member is required to invest a total of about $130 \mathrm{~h}$ over the course of approximately one year.

\section{Method}

The UTQ program is facilitated by a qualified educationalist (coach). Participating teachers work independently over the course of the programme on putting together a UTQ portfolio. During the programme, they discuss their interim portfolio products with each other and their coach in feedback meetings. The products consist of teaching materials that lend insight into their didactic competencies, selfassessments and evaluations by third parties. The portfolio is finally assessed by a UTQ portfolio examination committee. The UTQ certificate will be issued upon obtaining a positive assessment.

The programme involves the following components:

1. An Introductory meeting with the aim to create a feeling of fellowship, to fully inform participants of the plans and to ensure that expectations are in general agreement. It is important to plan a collective starting point. The $2 \mathrm{~h}$ course consists of an information session, and discussing and answering questions. In preparation participants have to fill in an intake form, and read the programme setup.

\section{Refresher course}

This module about active teaching and constructively aligned teaching covers basic concepts such as learning goals, teaching methods and testing, all of which are applied in the training of the participants by means of practical assignments and exercises. The assignments and exercises are input for the portfolio. The course is in the form of a $3 \times 3.5$-h workshops: interpretation, assignments, exercises, self-motivation, feedback, questionand-answer sessions and discussion. Participants have to do homework assignments.

\section{Compiling a portfolio}

Each participant has to compile a portfolio by collecting teaching material and validations, and writing self-assessments. They have to peruse and respond to (parts of) the portfolios of other participants, and process the feedback of colleagues. The total workload of 
Table B1. UTQ Competence profile with final achievement levels.

\begin{tabular}{ll}
\hline A & Developing teaching; the lecturer can: \\
\hline 1. re(develop) a course using specifically formulated learning objectives \\
2. develop effective, efficient and Active learning methods and also choose and/or develop \\
suitable study materials in order to achieve the learning objectives \\
3. take the teaching context of the institute/faculty into account \\
4. take the entry levels of the students into account \\
5. take the specific didactic requirements of the discipline into account \\
6. demonstrate a relationship between the content of the course components he/she teaches \\
7. design a test plan, including assessment criteria and, using this, develop tests to check \\
\hline B Implementing teaching; the lecturer can: \\
\hline 1. provide insight into the formulated learning objectives or competences \\
2. use the formulated learning objectives and the students' entry levels to choose effective \\
3. motivate students to interpret and design their own learning process \\
4. use technical aids in a didactically suitable manner. \\
5. supervise groups of and individual students and give them effective feedback during the \\
7. learning process \\
8. apport students in their development of academic skills
\end{tabular}

C Organising and coordinating teaching; the lecturer can:

1. work in a team (e.g. course committees, semester/annual meetings) to agree on activities and to collaborate with colleagues

2. plan teaching materials, exams, integration of administrative tasks and completion of teaching activities so they are logistically feasible and are implemented on time

3. describe university and faculty regulations that are relevant to the teaching process, such as the Course and Examination Regulations and the role of relevant bodies, such as the Board of Examiners, Board of Studies and the department administration.

D Evaluating teaching; the lecturer can:

1. compile an evaluation plan, implement and analyse the evaluation results and draw conclusions about his/her teaching quality

2. analyse test results and draw conclusions on the quality of learning, teaching and testing

3. formulate and implement enhancements that have been recommended for both teaching processes and products.

E Professionalisation; the lecturer can:

1. acquire an understanding of developments in the didactics of higher education and also apply them in such a way that the methods used match established learning objectives or competences.

2. reflect on his/her own work and the students' work, and is aware of any problem areas in the way he/she performs.

3. reflect on his/her own performance and then formulate resolutions to improve activities and personal objectives relating to professional development. 
compiling a portfolio is about $80 \mathrm{~h}$. A full description on the content of a portfolio is given below.

\section{Feedback meetings}

Teachers learn well and willingly from each other. Every 6 weeks $2 \mathrm{~h}$ feedback meetings are held so that they can help each other to compile their portfolios. In these, they are assisted by a UTQ coach. They are able to explain their teaching material, self-assessments and difficult situations, and process the tips and solutions they receive into their critical self-assessments. They have to read and formulate feedback on portfolios of fellow participants.

\section{Observing and delivering lectures}

The aim of this activity is learning to reflect on lectures given by colleagues, awareness of important points in the delivery of a good lecture, discovering what succeeds and what requires improvement, and identifying and formulating points for improvement. Use is made of an observation form and when possible: making a video recording, followed by a discussion and reporting by the teacher who gave the lecture.

6. Optional: taking a didactic course

In order to write a good self-assessment and have sufficient didactic material to take to the feedback meetings, participants may take a didactic course on a subject that best suits their experience, interests and tasks. This course could deliver products that can be included in the participant's portfolio.

7. Optional: coaching on the job

If lecturers would like to receive more feedback on their teaching practice they can ask the UTQ coach to attend their class. Afterwards the coach will discuss the teaching activity.

\section{Portfolio}

The compilation of a (digital) portfolio is the core activity of this programme: the portfolio should reflect the didactic competencies of the participant in the programme and will be assessed as such.

Competences are demonstrated by means of the teaching portfolio which contains three sorts of products for three different type of teaching: teaching materials, validation reports and self-reflection reports.

The participants may take three thematic areas out of the following list to base their portfolio work on:

1. Classroom teaching

2. Individual teaching (thesis supervision)
3. International teaching

4. Online teaching.

Each theme presented in the portfolio should cover three aspects:

1. Evidence: These are documents being developed. They have to demonstrate that the lecturer has acquired certain didactic competences (e.g. a lesson plan, design assignments, video recording, tests etc.).

2. Validation: Validation means that others reflect critically on parts of the portfolio and activities, both in terms of content and the manner in which the lecturer described/ implemented them. Validation can be done by students, colleagues, the coach, management, fellow UTQ participants etc.

3. Reflection: These documents contain descriptions of the own point of view on how the whole process of acquiring a certain competence has gone. The lecturer analyses his/her own strong and weak points in terms of didactic competences. Which choices were made and why? What went well? What was difficult? Would things have to be doen differently in the future?

In addition to the above described components, the portfolio also contains an explanation of how the products in the portfolio are related. This explanation should make clear what the materials consist of, how much he/she contributed to the materials or their development, why this piece of evidence is included and what the context of this material is (place in the academic year/curriculum).

\section{Assessment}

The portfolios of the participants are submitted to an independent portfolio commission, to be appointed and consisting of three individuals. This committee will assess the portfolios in accordance with a specially established procedure and using the assessment criteria established for the purpose. The committee is expected to come to a consensus in mutual consultation.

\section{Supplementary material related to this article is available online at: http://www.hydrol-earth-syst-sci.net/ 16/3677/2012/hess-16-3677-2012-supplement.zip.}

Acknowledgements. The authors thank the staff members of UNESCO-IHE who anonymously participated in the surveys.

Edited by: J. Seibert 


\section{References}

Ashby, E.: The structure of higher education: A world view, High. Educ., 2, 142-151, doi:10.1007/BF00137744, 1973.

Bennett, N.: Teaching Styles and Pupil Progress, Open Books Publishing Ltd, p. 216, 1976.

Biggs, J. and Tang, C.: Teaching for Quality Learning at University, Society for Research Into Higher Education, Open University Press, 480, 2011.

Cottrell, A. and Lucchetti, R.: Gretl User's Guide, available at: http: //ricardo.ecn.wfu.edu/pub//gretl/manual/en/gretl-guide.pdf, last access: 15 November 2011.

Eble, K. E. (Ed.): Teaching styles and faculty behavior, in: Improving teaching styles, Jossey-Bass, San Francisco, CA, 1980.

Felder, R. M. and Silverman, L. K.: Learning and teaching styles in engineering education, available at:http://winbev.pbworks.com/ f/LS-1988.pdf (last access: 7 March 2012), Eng. Educ., 78, 674681,1988

Grasha, A. F.: A matter of style: The teacher as expert, formal authority, personal model, facilitator, and delegator, College Teach., 42, 142-149, 1994.

Grasha, A. F.: Teaching With Style: The Integration of Teaching and Learning Styles in the Classroom, Alliance Publishers,Pittsburgh, USA, 1996.

Grasha, A. F. and Yangarber-Hicks, N.: Integrating Teaching Styles and Learning Styles with Instructional Technology, College Teach., 48, 2-10, 2000.

Jury, W. A. and Vaux, H.: The role of science in solving the world's emerging water problems, P. Natl. Acad. Sci. USA, 102, 1571515720, doi:10.1073/pnas.0506467102, 2005.

Kleinhans, M. G., Bierkens, M. F. P., and van der Perk, M.: HESS Opinions On the use of laboratory experimentation: "Hydrologists, bring out shovels and garden hoses and hit the dirt", Hydrol. Earth Syst. Sci., 14, 369-382, doi:10.5194/hess-14-3692010, 2010.

LimeSurvey user manual (n.d.): available at: http://docs.limesurvey. org/English+Instructions+for+LimeSurvey\&structure=English+ Instructions+for+LimeSurvey, last access: 21 November 2011.
Lucas, S. B.: Who am I? The influence of teacher beliefs on the incorporation of instructional technology by higher education faculty, Chemistry \& biodiversity, The University of Alabama Tuscaloosa, retrieved from http://susanlucas.com/dissertation. pdf (last access: 16 October 2012), 2005.

Lucas, S. B. and Wright, V. H.: Who am I? The influence of teacher beliefs on instructional technology incorporation, J. Excell. College Teach., 20, 77-95, 2009.

Mann, H. B. and Whitney, D. R.: On a Test of Whether one of Two Random Variables is Stochastically Larger than the Other, Ann Math. Stat., 18, 50-60, doi:10.1214/aoms/1177730491, 1947.

Pathirana, A., Gersonius, B., and Radhakrishnan, M.: Web 2.0 collaboration tool to support student research in hydrology - an opinion, Hydrol. Earth Syst. Sci., 16, 2499-2509, doi:10.5194/hess-16-2499-2012, 2012.

Postareff, L., Lindblom-Ylänne, S., and Nevgi, A.: The effect of pedagogical training on teaching in higher education, Teach. Teach. Educ., 23, 557-571, doi:10.1016/j.tate.2006.11.013, 2007.

Quirk, M. E.: How to Learn and Teach in Medical School, Charles C. Thomas, Springfield, IL, 1994.

Short, E. C.: Knowledge and the educative functions of a university: designing the curriculum of higher education,available at: http://www.tandfonline.com/doi/abs/10.1080/ 00220270110069181 (last access: 7 March 2012), J. Curriculum Stud., 34, 139-148, 2002.

Solomon, D.: Teacher Behavior Dimensions, Course Characteristics, and Student Evaluations of Teachers, Daniel Solomon American Educational Research Journal, 3, 35-47, 1966.

Uhlenbrook, S.: Catchment hydrology - a science in which all processes are preferential, Hydrol. Process. Today, 20, 3581-3585, doi:10.1002/hyp.6564, 2006.

Uhlenbrook, S. and de Jong, E.: T-shaped competency profile for water professionals of the future, Hydrol. Earth Syst. Sci. Discuss., 9, 2935-2957, doi:10.5194/hessd-9-2935-2012, 2012.

Wagener, T., Sivapalan, M., Troch, P. A., McGlynn, B. L., Harman, C. J., Gupta, H. V., Kumar, P., Rao, P. S. C., Basu, N. B., and Wilson, J. S.: The future of hydrology: An evolving science for a changing world, Water Resour. Res., 46, W05301, doi:10.1029/2009WR008906, 2010. 